\title{
Utilization of Data Center Waste Heat in Northern Ostrobothnia
}

\author{
Tero Leppänen*, Rihard Romka, Pekka Tervonen
}

\begin{abstract}
Data center industry is growing rapidly due to the expanding internet traffic and the upcoming loT revolution. Data centers consume vast amounts of energy globally and are also a significant source of greenhouse gas emissions. There is a need to improve energy efficiency and sustainability of data center operations. The energy consumed by data centers is mostly converted to heat and this study focuses on utilizing that waste heat according to the principles of circular economy in the context of Northern Ostrobothnia, Finland. The overall regional business potential of data center waste heat utilization is evaluated and the best options of utilizing waste heat in case data center are sought. The study found that the most viable option would be utilizing waste heat locally to heat facilities or in industrial processes. Another potential option is to connect data center into a district heating system where waste heat can be fed.
\end{abstract}

Keywords: by-product utilization; circular economy; data center; sustainability; waste heat

\section{INTRODUCTION}

As the data center industry is growing rapidly due to the expanding internet traffic and the upcoming IoT (Internet of Things) revolution, data center technology must be prepared to become more dynamic and scalable. These changes in the industry are forcing data center energy efficiency to become increasingly more important. The total global electricity consumption of data centers was estimated $198 \mathrm{TW} \cdot \mathrm{h}$ in 2018 [1] and the greenhouse gas emissions of ICT sector including data centers have grown to match $2 \%$ of the total global emissions and data centers have the sector's fastest growing carbon footprint [2]. The energy used to run a data center mostly converts to heat. Only recently this heat is becoming utilized by mostly large commercial data center companies. The practice is quickly catching on.

Finland has enormous growth opportunities for the data center industry. The cold climate, world-class energy infrastructure and skilled workforce give Finland an advantage as a location for future data center investments. [3]
According to an estimate by Boston Consulting Group, a data center investment of EUR 400 million could generate an economic impact of EUR 1 billion and create over 4500 jobs [4]. At this moment individual Finnish companies involved in the data center industry are too small to compete against multinational corporations. Thus, it would be wise to increase cooperation and to create efficient value chains and business ecosystems that involve multiple actors from building, energy production, to the digital industry itself. In the case of Northern Ostrobothnia, the same realities and possibilities are present. This study aims to answer the following research questions (Fig. 1):

- RQ1: What factors affect waste heat utilization in data centers?

- RQ2: What are the location specific factors that affect the data center industry?

- RQ3: How to best utilize waste heat produced by data centers in Northern Ostrobothnia?

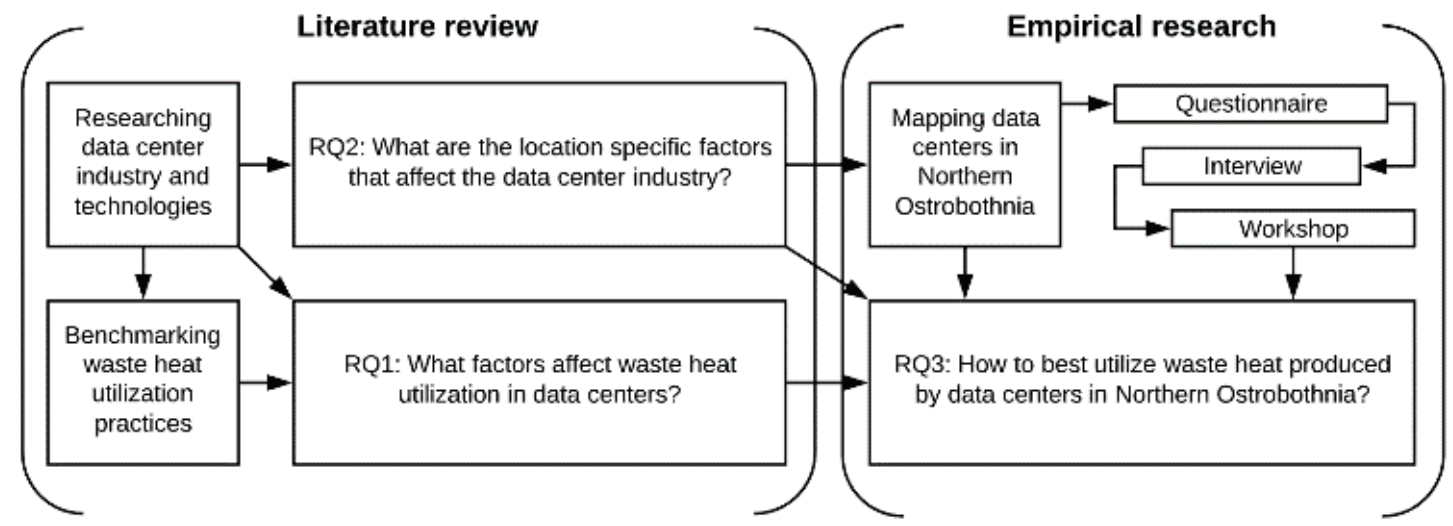

Figure 1 Research process

\section{MATERIALS AND METHODS}

The study on waste heat utilization from data centers located in Northern Ostrobothnia began by reviewing articles related to data center solutions and technologies and benchmarking potential waste heat utilization practices as well as studying different relevant factors that need to be taken into account in the data center industry, for example, the effects of location on data center energy efficiency referred in this article as location specific factors. 
The data collection included a questionnaire, an interview and a workshop session. The research focused on data centers in the private sector that provide commercial services. After mapping the data centers in Northern Ostrobothnia, their cases were studied, and a questionnaire sent. One interview was conducted with a party responsible for planning to build a data center in the Northern Ostrobothnia region. Lastly a workshop session was organized for data center entrepreneurs, researchers and other industry experts. All companies and related parties will remain anonymous in this article. The research process is illustrated in Fig. 1.

\section{LITERATURE REVIEW}

In order to pinpoint the best suitable technologies for waste heat utilization in data centers, it is important to take into account the relevant factors that possibly affect the viable technologies. These factors will set the criteria for the technologies that can be used in the specific cases and will make it easier to discard unviable solutions. The factors reviewed in this study include geographical environment, information and energy infrastructure, political and social stability and availability of suitable and skilled workforce.

\subsection{Data Center Energy Efficiency}

Data center technology includes electricity, cooling, ITtech and lighting. Most of the energy consumed by electrical and IT-systems transforms into heat. The cooling systems can in some cases use up to half of the electricity used in data centers, and therefore they have the largest potential in saving energy. Most of the electricity is usually used by the servers and there is little that can be done to lower that usage. The servers and the cooling systems together are responsible for using over $60 \%$ of all the energy consumed by the data center and other systems such as lighting, UPS-system (uninterrupted power supply), ventilation and other nonproductive elements are responsible for the remaining energy consumption. Fig. 2 illustrates power allocation in a typical data center [5].

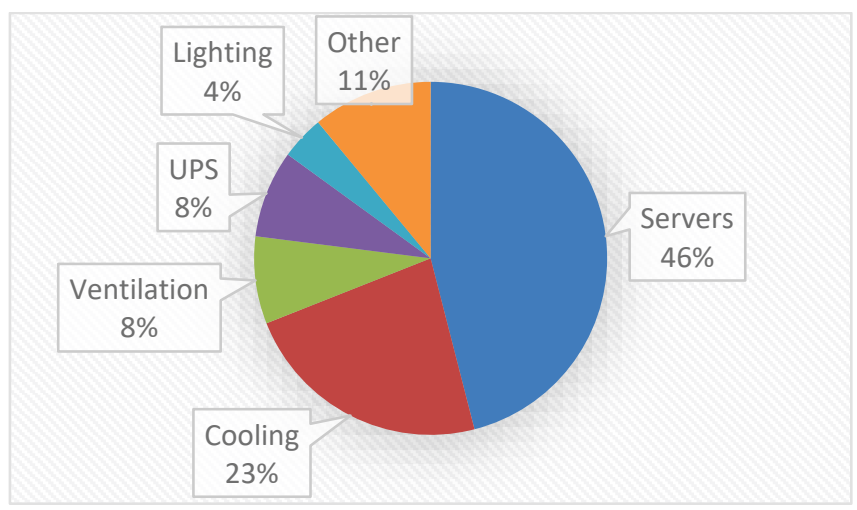

Figure 2 Power allocation in a typical data center [5]

\subsection{Data Center Cooling}

A substantial amount of heat is produced in the server rooms of data centers. This heat needs to be directed out of the facilities as the optimal temperature of air in the server rooms needs to be in the range of $18-27^{\circ} \mathrm{C}$ [6]. To regulate the temperature in the server room of a data center different types of cooling systems can be applied. The cooling systems are normally designed individually for each data center.

Servers are typically placed in racks in a manner that leave hot and cold aisles in between the servers. This allows cooling air to flow to the front of the server and exit as heat from the back of the rack. It is important that the cold and hot aisles are insulated so that waste heat and the cooling air do not mix. The heat energy is then directed out of the server room and can be used in waste heat applications. Data center cooling solutions are various and most often case specific. The most common solutions use both free cooling and mechanical refrigeration, as using only mechanical cooling is less energy efficient. [7]

Free cooling solutions typically use the cooling capacity of outside air, water from a natural water source or ground to cool water to be used in cooling of the server racks. The possibility of using free cooling depends heavily on location specific factors such as geography and climate. In cases where free cooling is not enough, mechanical refrigeration can be added to provide the additional cooling energy. Other potential cooling methods for data centers include liquid cooling such as sorption cooling and district cooling. Sorption cooling can utilize waste heat from the servers and is thus a highly potential solution for data centers to use. [8] District cooling is an emerging technology that uses the same technology as district heating. The cooling energy can be produced by heat pumps or by utilizing a natural source of cool water such as a sea or a lake.

\subsection{Location Specific Factors}

The demand for data centers is increasing exponentially in the EU and the continuous growth is dependent on the digitalization of Europe. It must be taken in to account, that a data center situated in Finland does not only serve Finnish clients, but the entire European market. In principle, data centers are not dependent on location and can be built anywhere. For optimal operation it is still reasonable to take the geographic and environmental factors into account when choosing a location. Different factors related to the location of data centers were studied in a research conducted by Cushman \& Wakefield in 2016 [9]. The most impactful factors are shown weighted in Tab. 1.

These factors can be divided into four categories: geography, information infrastructure, energy and stability.

\subsubsection{Geography}

When choosing a location for a data center, geographical location is a substantive factor. For the servers in the data center to work continuously, factors such as seismology, possible floods and other natural disasters as well as climate 
factors need to be taken into account. For example, a northern, colder climate allows cost-efficient cooling mechanisms such as air cooling or district cooling. The risk of natural disasters is weighted as the most important risk to take into account when choosing a data center location [9].

Table 1 Factors likely to affect the successful operation of data center [9]

\begin{tabular}{|l|r|}
\hline \multicolumn{1}{|c|}{ Criteria } & Weighting, \% \\
\hline Energy costs & 8.97 \\
\hline Internet bandwidth (Mbit/s) & 11.54 \\
\hline Ease of doing business (World Bank Rating) & 11.54 \\
\hline Corporate tax & 6.41 \\
\hline Political stability & 12.82 \\
\hline Sustainability (\% energy from alternatives) & 8.97 \\
\hline Natural disasters & 15.38 \\
\hline Energy security & 12.18 \\
\hline GDP per capita & 5.77 \\
\hline Water availability & 6.41 \\
\hline
\end{tabular}

Earthquakes in Finland are relatively weak ranging between 0-4 in magnitude [10] and according to a report by Cushman \& Wakefield [9], Finland is the fifth best in category "World risk assessment vulnerability and coping capacity (natural disaster / economic \& political challenges in urban areas)". Northern Ostrobothnia is situated between continental and oceanic climates in the subarctic zone. This climate allows for cold air to be used in data center cooling. The utilization of district cooling in Oulu has also been studied, but the shallowness of the Bothnian Bay results in high temperatures of water and thus the area lacks a yearround source of cold water. [11]

\subsubsection{Information Infrastructure}

Naturally data centers ought to be located in areas with good network infrastructure such as good internet connections with secure data cables and know-how. According to Mena et al. [12], the key factors when evaluating a site's network infrastructure are network capacity, redundancy and network reliability. It is important for a data center to secure the data in their servers from malware and spying. In many countries legislation allows mass surveillance of the network which hurt the reliability of commercial data centers. In Finland, such legislation has not yet been implemented and its regulatory environment remains superior to its competitors. The country does benefit from world-class network infrastructure. [3]

In 2016 a submarine communications cable was built connecting Finland with mainland Europe [13]. In addition, plans have been made to build a cable from Asia through the Northeast Passage to Finland and further to mainland Europe [14]. With these infrastructure improvements Finland has a tremendous opportunity to become the "Switzerland" of data centers.

\subsubsection{Energy}

The total global electricity consumption of data centers was estimated $198 \mathrm{TW} \cdot \mathrm{h}$ in 2018 [1] and the energy demand of data center operations has been growing steadily. Thus an uninterrupted energy supply and a working and reliable grid is essential for the stability of a data center. Ideally, a data center should receive power from two different grids, and more than one commercial utility provider ought to be near the site. Backup power can be provided using generators to avoid server downtime. Northern Ostrobothnia and Finland in general have the advantage of having state of the art energy infrastructure and technology level. The completion of the nuclear power plants of Olkiluoto 3 and Hanhikivi 1 will further secure energy independence and thus better the Finland position as a location for data centers.

\subsubsection{Stability}

In addition to a mature network and energy infrastructure, a stable political and social environment is also important for data centers. According to Benáček et al. [15], countries that have transparent and efficient institutions are more likely to attract foreign investors and have more predictability in their regulations. A secure political situation guarantees that the data center operations and the data hosted in the data center are safe and secured. Political stability was listed as the second most important factor in choosing a data center location. In 2016, Finland ranked 9th in the world on political stability in the Data Centre Risk Index of Cushman \& Wakefield [9].

\subsection{Utilization of Waste Heat}

Data center waste heat is energy that leaves the data center as cooling water, air or condensation heat via cooling system. Currently most data centers do not utilize their waste heat in any way. The turn towards green energy production and the EU targets [16] of having 32\% of energy being produced by renewables by 2030 and improving energy efficiency by $32.5 \%$ by 2030 , has encouraged to find solutions for the reuse of data center waste heat. In the case of Finland, over $37 \%$ of industrial waste heat is simply released into the environment. This accounts for about 54 TW $\cdot h$ of heat energy. [17] Industrial waste heat can be used in a wide range of applications such as the heating of nearby facilities, controlling the temperature of greenhouses and aquaculture facilities, drying biomasses as well as district heating. Data center waste heat is well suitable for district heating purposes because of its stable and steady supply flow. However, the waste heat from data centers is of low temperature, typically between $25-60{ }^{\circ} \mathrm{C}$, too low to be used in traditional thermodynamic processes. The temperatures used in district heating are between $70-110^{\circ} \mathrm{C}$, depending on the season. Heat pumps can be used to increase the temperature of waste heat but require substantial investment and thus, long-term prospects and an economic incentive.

\subsubsection{Heating}

The most direct and straightforward way of utilizing data center waste heat is heating. The waste heat can be directed to heat the data center itself, or other facilities in the proximity of the data center. As mentioned before, majority 
of data center waste heat is too low-grade to be used in district heating directly. Heat pumps are commonly used technology in the industrial sector and are suitable for raising the temperature of low-grade heat in industrial processes. Heat pumps can also be connected in parallel to achieve more power. Investing in a heat pump is profitable, when the difference in the price of heat generated, and the energy used by the heat pump, is of benefit to the investor and the payback period is short. Heat pump expenses vary and are assessed case-by-case.

A study was conducted by Kupiainen [18] in which two different cooling options were compared for a data center in the Futura building in Jyväskylä, Finland. The results showed that applying a heat pump with free cooling could potentially provide lifetime savings of $€ 280,000$ in 20 years when compared to applying free cooling and a refrigeration machine.

\subsubsection{District Heating}

District heating is a common technology in the Northern Hemisphere. District heating systems can distribute heat from a centralized location to residential and commercial heating requirements. Steam or hot water can be piped underground to individual buildings where it is used for heating, hot water consumption or air conditioning. District heat can be produced in several ways such as burning fossil fuels, biomass, geothermal heating, heat pumps, solar and nuclear power. As reported by Andrews et al. [19] district heating produced in combined heat and power plants (CHP) have one of the lowest carbon footprints. Such systems are exceptionally common in Finland and Sweden. As mentioned before, currently the temperatures used in district heating are between $70-80{ }^{\circ} \mathrm{C}$ in the summer season, and $100-115^{\circ} \mathrm{C}$ in the winter season respectively. As the building industry is striving to find solutions to more insulated housing and new $4^{\text {th }}$ generation district heating technologies are developed, these temperatures used may see a steady drop, which could allow feeding lower quality heat into the district heating network. Data center waste heat could be used in preheating feedwater of a power plant as suggested by Marcinichen et al. [20] This type of utilization can save fuel in the power plant as the operation time of a feedwater preheater can be cut down.

\subsubsection{Electricity Production}

Electricity can be produced using the waste heat from data centers. At this moment the most promising solutions are mostly based on the Organic Rankine Cycle (ORC). The Organic Rankine Cycle is similar to the Rankine cycle-based systems commonly used in steam turbine systems, but instead of water, uses an organic, high molecular mass fluid with a liquid to vapor phase change, occurring at a lower temperature than water. This allows ORC-technology to use waste heat as power. The technology works best provided with constant heat of over $100{ }^{\circ} \mathrm{C}$ but can be used in lower temperatures as well. Several ORC power plants have been installed in the MW range, but according to Tocci et al. [21] the commercialization of ORC power plants in the $\mathrm{kW}$ range have not reached a high level of maturity mainly because of economic reasons as well as lack of awareness. Ebrahimi et al. [22] studied implementing an ORC-system in a data center for the reuse of waste heat and estimated a payback period between $4-8$ years in data center environments.

\subsubsection{Cooling}

Waste heat can be also used in cooling using sorption cooling technologies. Sorption technologies use a source of heat to produce cold. This characteristic makes sorptionbased cooling technologies useful in waste heat reuse. The term sorption cooling technologies is used to describe both absorption and adsorption cooling. Absorption cooling system is the more common of the two. It is similar to vapor compression cycles but instead of compressing refrigerant vapor, it dissolves this vapor into liquid that is then pumped into a higher pressure and then uses the heat input to evaporate the refrigerant vapor out of the solution. Absorption cooling is specifically economical when the temperature of the waste heat is between $90-160{ }^{\circ} \mathrm{C}$ [23].

The adsorption process is similar, but instead of a liquid, the working fluid adsorbs into the surface of a solid. In comparison with liquid absorption systems, adsorption systems present the advantage of being able to be powered by a large range of heat sources. Adsorption processes can run in relatively low temperatures starting from $50^{\circ} \mathrm{C}$ and are thus suitable for data center waste heat solutions [24].

\subsubsection{Industrial Processes}

Numerous industrial processes can use waste heat as an energy source, depending on the quality and temperature of the waste heat and the process itself. Low grade waste heat is commonly used to heat facilities, dry biomasses or in district heating. Low grade waste heat is best used on-site, as it is most energy efficient and investing in a larger network is often not cost effective and the storage of heat energy problematic. In the case of data center waste heat, the drying of biomasses is one potential application. Drying usually takes place in temperatures ranging from $25-60^{\circ} \mathrm{C}$, well in the range of data center waste heat. Using data center waste heat in drying can be challenging due to logistical reasons. Drying biomasses near the place they are obtained is more cost effective, whereas data centers are mostly located in the cities. Another promising application of waste heat are greenhouses. The temperature in greenhouses is kept around $25^{\circ} \mathrm{C}$. A data center provides a constant flow of low grade waste heat and can thus allow a greenhouse to function yearround. Similarly, fish farms using indoor recirculating aquaculture systems, can use data center waste heat to control water temperatures.

\subsubsection{Carbon Footprint}

Data centers are major consumers of energy. A large share of energy is consumed by the servers themselves and the cooling systems. According to Bouley [25], the emissions 
caused by a data center mainly depend on three factors, the location of the data center, the IT load and electrical efficiency. The energy production method also plays a role. If hydro or nuclear power is available, emissions are naturally lower compared to fossil fuel driven energy production. When estimating the carbon footprint of a data center one must account the emissions caused by the building "shell" itself, and the embedded carbon in it. Data center facilities themselves are relatively simple by design. Bouley estimates that in a data center of $1 \mathrm{MW}$ electrical power and $530 \mathrm{~m}^{2}$ there is 128.3 tons of $\mathrm{CO}_{2}$ embedded. Carbon emissions, when recovering waste heat for district heating purposes depend on the fuel used and the technical demands of the district heating network itself. Marcinichen et al. [20] have suggested that utilizing data center waste heat in a nearby power plant could increase the energy efficiency of the power plant by up to $2.2 \%$ as well as cut $\mathrm{CO}_{2}$ emissions. Data center waste heat can in theory replace some of the fuel used in heat production, and thus lower the carbon emissions. This applies specifically to heat power plants. In the case of CHP plants, the replacement is more complicated, as the replaced heat would also be taken away from electricity production and thus it possibly would not be economically attractive for energy producers.

\section{DATA CENTERS OF NORTHERN OSTROBOTHNIA}

One of the central goals of this study was to investigate the data centers of Northern Ostrobothnia. Defining a data center can be challenging as any space with a server and a hard drive can be defined as a data center. In this study the focus was limited to commercial data centers. When mapping the data centers in Northern Ostrobothnia, it was found that most were concentrated to the metropolitan area of Oulu. This is not surprising, as most data centers are located in urban areas with good IT and energy infrastructure as well as available skilled workforce. As the recovery of waste heat from data centers is a relatively new phenomenon, it is not surprising that only fraction of waste heat from data centers in Finland is recovered. Such was the case in Northern Ostrobothnia as well. As the data centers mapped were of relatively small size, mostly server rooms that rented their facilities, none of them had plans to recover waste heat. The studied data centers are heated by district heating from a local producer. No large data centers have yet been built in Northern Ostrobothnia.

\section{RESULTS AND DISCUSSION}

When researching potential data center waste heat utilization solutions in Northern Ostrobothnia, it was discovered that the most viable option would be to use the heat energy to heat the data center facilities themselves, or possible physically adjacent facilities. This type of solution could allow year-round greenhouses, indoor fish farms, offices and residential buildings. To connect the waste heat source into a district heating system is challenging and not cost-effective, due to the low price of CHP produced district heat, as well as the technical specifications of the network itself. With implementing two-way heat networks, the profitability could rise, as heat could be bought and sold between the provider and the receiver, though turning an existing district heating network in to a two-way network requires investments and technical changes. Two-way network solutions are more simply implemented in newly built sites.

The use of data center waste heat for cooling solutions was researched as well. In the case of Northern Ostrobothnia, using outdoor air or free cooling was the most viable approach as the outdoor temperatures are relatively low throughout the year. In addition, investing in sorption systems would require an additional investment in a heat pump to raise the temperature of waste heat. The low efficiency of these systems lowers profitability as well.

Electricity production with ORC-technology using waste heat is a technically viable alternative. However, in Northern Ostrobothnia the low price of electricity makes the solution lose its cost-effectiveness. The waste heat recovered would need to be practically free for the investment to be profitable. Thus, with the current electricity prices the payback times are too long.

All in all, the data center industry is exponentially growing, and the Northern Ostrobothnia has excellent potential to be a key player on the field in Finland. It would take more awareness and cohesion from different parties involved in the business in private and public sectors. It is important to look outside the box to whether different actors in the fields related could provide valuable new insights regarding the data center itself and its relation and integration with industrial and urban environments. As technology advances and the price of energy rises, waste heat recovery solutions that were earlier unprofitable could become costeffective. The two-way district heat network could encourage producing energy locally in smaller communities.

The construction of the Northeast Passage submarine communications cable will naturally attract more data center building projects in Finland. Thus, it is important for Finland to keep data centers in a prioritized position and to attract investments that will increase the know-how and boost innovation not only in data center design, construction and maintenance but in energy, ICT and other adjacent sectors as well.

When it comes to data centers, Finland and Northern Ostrobothnia need a clear vision and plan to advance the data center industry. Giving up a certain type of pragmatism and having a more open approach could give a boost to the overall economy. Energy efficiency and possibilities for industrial symbioses and other circular economy solutions should be researched early on in data center planning processes.

\section{Notice}

The paper will be presented at MOTSP 2020 International Conference Management of Technology - Step to Sustainable Production, which will take place from $30^{\text {th }}$ September $-2^{\text {nd }}$ October 2020 in Bol, island Brač (Croatia). The paper will not be published anywhere else. 


\section{REFERENCES}

[1] IEA. (2019). Tracking Buildings, https://www.iea.org/ reports/tracking-buildings/data-centres-and-data-transmissionnetworks. Cited 25.2.2020.

[2] Avgerinou, M., Bertoldi, P., \& Castellazzi, L. (2017). Trends in Data Centre Energy Consumption under the European Code of Conduct for Data Centre Energy Efficiency. Energies, 10(10), 1470. https://doi.org/10.3390/en10101470

[3] Nissilä, J., Eho, J., \& Kokkonen, V. (2015). Finland's Giant Data Center Opportunity - From the Industrial Heartland to Digital Age. Oxford Research.

[4] Clipp, C., Larby, H., Lind, F., Lundmark, A. \& Morin, M. (2014). Digital Infrastructure and Economic Development An Impact Assessment of Facebook's Data Center in Northern Sweden. The Boston Consulting Group.

[5] Hewlett-Packard. (2009). A Blueprint for Reducing Energy Costs in Your Data Center.

[6] ASHRAE. (2011). 2011 Thermal Guidelines for Fata Processing Environments - Expanded Data Center Classes and Usage Guidance. Retrieved from https://ecoinfo.cnrs.fr/ IMG/pdf/ashrae_2011_thermal_guidelines_data_center.pdf

[7] Merilä, M. (2016). Datakeskusten hukkalämmön talteenotto ja hyödyntäminen. Bachelor's Thesis, KYAMK University of Applied Sciences.

[8] Wahlroos, M., Pärssinen, M., Manner, J., \& Syri, S. (2017). Utilizing data center waste heat in district heating - Impacts on energy efficiency and prospects for low-temperature district heating networks. Energy, 140(1), 1228-1238. https://doi.org/10.1016/j.energy.2017.08.078

[9] Cushman \& Wakefield. (2016). Data Center Risk Index Informing Global Location Strategies in a Digital World Expanding at a Phenomenal Pace. Retrieved from https://verne-global-lackey.s3.amazonaws.com/uploads\%2F2 017\%2F1\%2Fb5e0a0da-5ad2-01b3-1eb8-8f782f22a534\%2F C\%26W Data Centre+Risk Index Report 2016.pdf

[10] University of Helsinki, Institute ${ }^{-}$of Seismology. (2020). Earthquakes in Finland. https://www.helsinki.fi/en/instituteof-seismology/earthquakes-in-finland. Cited 19.5.2020.

[11] Kilpeläinen, J. (2011). Kaukojäähdytyksen potentiaali ja kannattavuus Oulun keskustan alueella. Master's Thesis, LUT University. (in Finish)

[12] Mena, M., Musilli, J., Austin, E., Lee, J., \& Vaccaro, P. (2014). Selecting a Data Center Site: Intel's Approach. Retrieved from https://media14.connectedsocialmedia.com/intel/02/11447/IT Best_Practices_Data_Center_Site_Selection.pdf

[13] Cinia. (2020). Cinia C-Lion1 Submarine Cable. https://www.cinia.fi/en/services/international-connectivityservices/c-lion1-submarine-cable.html. Cited 26.2.2020.

[14] Cinia. (2019). Arctic Telecom Cable Initiative Takes Major Step Forward. https://www.cinia.fi/en/archive/arctic-telecomcable-initiative-takes-major-step-forward.html.

[15] Benáček, V., Lenihan, H., Andreosso-O'Callaghan, B., Michaliková, E., \& Kan, D. (2014). Political risk, Institutions and Foreign Direct Investment: How Do They Relate in Various European Countries? The World Economy, 37(5), 625653. https://doi.org/10.1111/twec.12112

[16] European Commission. (2020). 2030 climate \& energy framework. https://ec.europa.eu/clima/policies/strategies/2030 Cited 25.2.2020.

[17] Motiva. (2013). Tuotannon hukkalämpö hyödyksi. Retrieved from https://www.motiva.fi/ajankohtaista/julkaisut/teollisuus/ tuotannon_hukkalampo_hyodyksi.10766.shtml
[18] Kupiainen, M. (2014). Lämpöpumppu konesalin jäähdytyksessä ja lämmöntalteenotossa. Bachelor's Thesis. Mikkeli University of Applied Sciences. (in Finish)

[19] Andrews, D., Krook Riekkola, A., Tzimas, E., Serpa, J., Carlsson, J., Pardo-Garcia, N. \& Papaioannou, I. (2012). Background Report on EU-27 District Heating and Cooling Potentials, Barriers, Best Practice and Measures of Promotion. Scientific and Policy Report by the Joint Research Centre of the European Commission.

[20] Marcinichen, J., Olivier, J. \& Thome, J. (2012). On-chip twophase cooling of datacenters: Cooling system and energy recovery evaluation. Applied Thermal Engineering, 41, 36-51. https://doi.org/10.1016/j.applthermaleng.2011.12.008

[21] Tocci, L., Pal, T., Pesmazoglou, I. \& Franchetti, B. (2017). Small Scale Organic Rankine Cycle (ORC): A TechnoEconomic Review. Energies, 10(4), 413. https://doi.org/10.3390/en10040413

[22] Ebrahimi, K., Jones, G., \& Fleischer, A. (2017). The viability of ultra low temperature waste heat recovery using organic Rankine cycle in dual loop data center applications. Applied Thermal Engineering, 126, 393-406. https://doi.org/10.1016/j.applthermaleng.2017.07.001

[23] Finnish Ministry of the Environment. (2011) Jäähdytysjärjestelmien energialaskentaopas 2011 (file:///C:/Users/korisnik/Downloads/J\%C3\%A4\%C3\%A4hdy tys_laskentaopas_12.9.2011-v2.pdf)

[24] Wang, R. \& Oliveira, R. (2006). Adsorption refrigeration-An efficient way to make good use of waste heat and solar energy. Progress in Energy and Combustion Science, 32(4), 424-458. https://doi.org/10.1016/j.pecs.2006.01.002

[25] Bouley, D. (2010). Estimating a Data Center's Electrical Carbon Footprint. Retrieved from https:/www.insight.com/ content/dam/insight/en_US/pdfs/apc/apc-estimating-datacenters-carbon-footprint.pdf

\section{Authors' contacts:}

Tero Leppänen, M.Sc.

(Corresponding author)

University of Oulu,

Pentti Kaiteran katu 1, Fl-90014 Oulu, Finland

tero.leppanen@oulu.fi

Rihard Romka, B.Sc.

University of Oulu,

Pentti Kaiteran katu 1, Fl-90014 Oulu, Finland

rihard.romka@oulu.fi

Pekka Tervonen, D.Sc.

University of Oulu,

Pentti Kaiteran katu 1, Fl-90014 Oulu, Finland

pekka.tervonen@oulu.fi 